\title{
EMOTIONAL STABILITY IN COLLIERY WORKERS
}

BY

\author{
ALASTAIR HERON and DOROTHY BRAITHWAITE \\ From the Medical Research Council Unit for Research in Occupational Adaptation and the \\ Nuffield Department of Occupational Health, University of Manchester
}

(RECEIVED FOR PUBLICATION JULY 3, 1952)

This paper reports the results obtained by using a small battery of objective tests of emotional stability in the clinical examination of a group of colliery workers. The main object of the investigation was to establish the incidence of rheumatic conditions among selected samples of office, maintenance, and underground workers at a particular colliery and these results have already been reported in this journal (Kellgren and Lawrence, 1952).

\section{Population Studied}

The total number of men involved in the present study was 184 of whom 76 were working underground. All the men were within the age-range 40 to 50 years.

\section{Tests}

The battery, taking about 30 minutes to administer, contained the following tests :-

Word Connection List (Crown, 1947, 1952).- The score is the number of " neurotic" responses marked in a list of 50 items consisting of a stimulus word followed by two response words.

Maudsley Medical Questionnaire (Eysenck, 1947, 1952).-A 40-item neuroticism inventory constructed empirically in terms of responses obtained from several thousand " normal " and "neurotic" subjects.

Leg Persistence Test (Eysenck, 1947).-This is scored as the number of seconds the seated subject is prepared to hold his leg fully extended above a nearby chair of the same height.

Annoyances List (Bennett, 1945). - The subject is asked to mark items which tend to annoy him from a list of 60 common annoyances.

Finger Dexterity Test (United States Employment Service, 1947).- This test is Section O (Assembly) from the General Aptitude Test Battery. The task involves the transfer of rivets from the upper to the lower half of a board, threading a washer on to the rivet en route.

There was evidence that each of these tests was capable of distinguishing significantly between groups of subjects (mainly soldiers) classed by psychiatrists as " neurotic" or " emotionally unstable" and other groups regarded as "normal". Factor analyses of batteries of such tests, including those listed above, had shown that they provided loadings on a general factor which may be called " emotional instability".

\section{Statistical Treatment of Results}

The range, mean, and standard deviation of raw scores for each test is shown in Table 1. These

TABLE 1 RAW SCORES

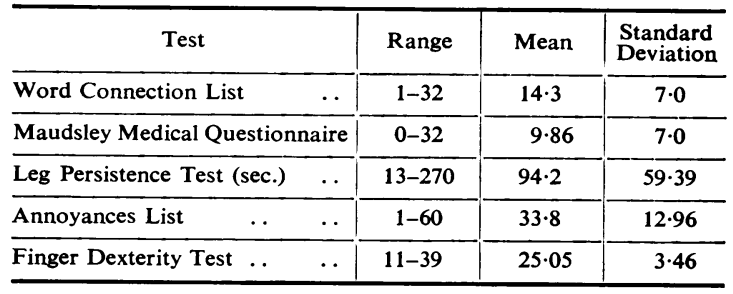

scores were converted into normalized percentile scores, using nine groups to facilitate Hollerith

TABLE 2 INTERCORRELATION MATRIX

\begin{tabular}{|c|c|c|c|c|c|}
\hline Test & $\begin{array}{c}\text { Scoring } \\
\text { Direc- } \\
\text { tion }\end{array}$ & 1 & 2 & 3 & 4 \\
\hline Word Connection List & High & - & - & - & - \\
\hline $\begin{array}{c}\text { Maudsley Medical } \\
\text { Questionnaire }\end{array}$ & High & $0 \cdot 128$ & - & - & - \\
\hline Leg Persistence Test & Short & 0.086 & $0 \cdot 221$ & - & - \\
\hline Annoyances List $\quad$. & Many & 0.040 & $0 \cdot 139$ & $0 \cdot 103$ & - \\
\hline Finger Dexterity Test. & Low & $0 \cdot 148$ & 0.013 & $0 \cdot 156$ & -0.009 \\
\hline
\end{tabular}

An $\mathrm{r}$ of 0.147 is significant at the 0.05 level. 
TABLE 3

\section{FACTOR* LOADINGS}

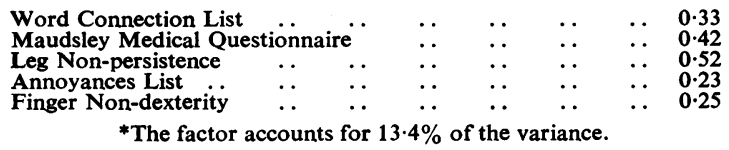

processing. Product moment correlation coefficients were then computed between each pair of variables. The resulting matrix (shown in Table 2) was then factor-analysed by Burt's simple summation method. A single factor was extracted for which loadings are shown in Table 3. The residual matrix is shown in Table 4, from which it will be observed that no

TABLE 4

RESIDUAL MATRIX

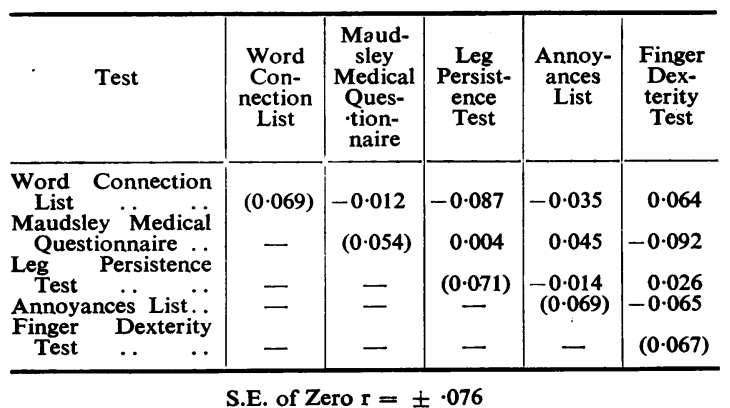

residual greatly exceeds the standard error of a zero correlation $(+0.076)$. The five tests provide a multiple correlation coefficient with the factor of 0.686 using Aitken's pivotal condensation method. The normalized percentile scores for each test were therefore combined to give a weighted composite score for each individual, referred to hereafter as the "emotional instability score". This process gives each man a score between 1 and 9 which locates him within the group studied. The cutting points for these scores are shown in Table 5. For example, if an individual has a score of 2 , he will be found among the $20(10 \cdot 7 \%)$ most emotionally stable, while another man with a score of 6 will be found among the $74(40 \cdot 2 \%)$ least emotionally stable, and a third with a score of 5 among the middle $36(19 \cdot 6 \%)$.

\section{Findings}

The examining physician in the rheumatism project, though not a psychiatrist, undertook to assess each man's mental state on a four-point scale without knowledge of the test results. This was later reduced to three by combining two adjacent categories. The final categories were described by him as follows :-(1) Positive mental health, well integrated $(39.6 \%)$; (2) doubtful, though no definite signs or symptoms $(49.7 \%)$; (3) presenting signs or symptoms of mental illhealth $(10 \cdot 7 \%)$.

The product moment correlation between this simple rating and the nine-point emotional instability score based on the objective tests is $+\mathbf{0 \cdot 3}$, which is significant $(P=0.001)$. The full distribution of the emotional instability scores against the physician's categories is shown in Table 6. (The

TABLE 6

COMPARISON OF PHYSICIAN'S CATEGORIES WITH NORMALIZED PERCENTILE SCORES (EMOTIONAL INSTABILITY)

\begin{tabular}{|c|c|c|c|c|c|c|c|c|c|c|c|c|}
\hline \multirow{2}{*}{\multicolumn{2}{|c|}{ Physician's Categories }} & \multirow{2}{*}{$\begin{array}{l}\text { No. of } \\
\text { Cases* }\end{array}$} & \multicolumn{10}{|c|}{ Emotional Instability Scores } \\
\hline & & & $\overline{1}$ & 2 & 3 & 4 & 5 & & & & 8 & 9 \\
\hline $\begin{array}{l}\text { (1) Well in } \\
\text { (2) Doubtf } \\
\text { (3) Signs o }\end{array}$ & $\begin{array}{cc}\text { ated } \quad . . \\
\ldots \\
\text { mptoms. }\end{array}$ & $\begin{array}{l}70 \\
88 \\
19\end{array}$ & $\begin{array}{l}5 \\
3 \\
0\end{array}$ & $\begin{array}{l}7 \\
5 \\
0\end{array}$ & $\begin{array}{r}12 \\
9 \\
0\end{array}$ & $\begin{array}{r}14 \\
13 \\
3\end{array}$ & 19 & & & & 4 & $\begin{array}{l}1 \\
6 \\
1\end{array}$ \\
\hline Totals & $\ldots$ & 177 & 8 & 12 & 21 & 30 & 35 & 3 & 2 & & 2 & 8 \\
\hline
\end{tabular}

*Seven cases seen by the psychologist were not seen by the physician, thus reducing the total to 177 when comparing results.

totals will serve as a reminder that while the former scores have been normalized the latter have not, a point which must be borne in mind during the ensuing argument.) The first thing to strike the eye is the group of zero entries in the bottom left-hand corner of the table, as one would expect from the existence of the significant correlation already quoted. However, it is also apparent that there is far from perfect agreement between the two associated measures, as again would be expected from so small a coefficient as $+0 \cdot 3$. In order to simplify evaluation of the data, Table 7 shows the result of dividing the emotional instability scores for each of the physician's categories at the mid-

TABLE 5

NORMALIZED PERCENTILE SCORES

\begin{tabular}{|c|c|c|c|c|c|c|c|c|c|c|c|c|}
\hline & & & & 1 & 2 & 3 & 4 & 5 & 6 & 7 & 8 & 9 \\
\hline $\begin{array}{l}\text { Number in each category } \\
\text { Percentage in each category } \\
\text { Ascending cutting points (No.) } \\
\text { Descending cüting points (No.) } \\
\text { ", ", (\%) }\end{array}$ & $\begin{array}{l}\ddot{*} \\
\ddot{*} \\
\ddot{\cdots}\end{array}$ & $\begin{array}{l}\ddot{*} \\
\ddot{*} \\
\ddot{\cdots}\end{array}$ & $\begin{array}{l}\ddot{*} \\
\ddot{*} \\
\ddot{\cdots}\end{array}$ & $\begin{array}{c}8 \\
4 \cdot 1 \\
8 \\
4 \cdot 1 \\
184 \\
100 \cdot 0\end{array}$ & $\begin{array}{l}12 \\
6 \cdot 6 \\
20 \\
10 \cdot 7 \\
176 \\
95 \cdot 9\end{array}$ & $\begin{array}{l}22 \\
12 \cdot 1 \\
42 \\
22 \cdot 8 \\
164 \\
89 \cdot 3\end{array}$ & $\begin{array}{l}32 \\
17 \cdot 4 \\
74 \\
40 \cdot 2 \\
142 \\
77 \cdot 2\end{array}$ & $\begin{array}{l}36 \\
19 \cdot 6 \\
110 \\
59 \cdot 8 \\
110 \\
59 \cdot 8\end{array}$ & $\begin{array}{l}32 \\
17 \cdot 4 \\
142 \\
77 \cdot 2 \\
74 \\
40 \cdot 2\end{array}$ & $\begin{array}{l}22 \\
12 \cdot 1 \\
164 \\
89 \cdot 3 \\
42 \\
22 \cdot 8\end{array}$ & $\begin{array}{l}12 \\
6 \cdot 6 \\
176 \\
95 \cdot 9 \\
20 \\
10 \cdot 7\end{array}$ & $\begin{array}{c}8 \\
4 \cdot 1 \\
184 \\
100 \cdot 0 \\
8 \\
4 \cdot 1\end{array}$ \\
\hline
\end{tabular}


TABLE 7

COMPARISON OF PHYSICIAN'S CATEGORIES WITH UPPER AND LOWER HALVES OF EMOTIONAL INSTABILITY SCORES

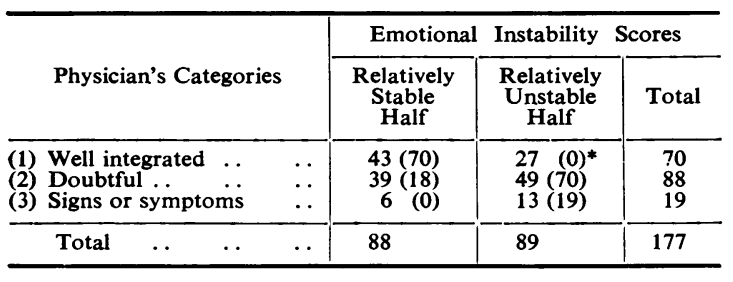

*Figures in brackets denote " expectations" (see text).

point, i.e., totals for scores 1 to 4 plus one-half of 5 form the " relatively stable" half, while totals for scores 6 to 9 plus one-half of 5 form the " relatively unstable" half. If there had been perfect agreement between the physician and the test-battery, one would expect to find no cases of the physician's category 1 (" definitely healthy ") in the " relatively unstable" half of the psychometric scores, and similarly no cases of the physician's category 3 in the "relatively stable" half. These expectations have been entered in parenthesis in the appropriate sections of the table, and the other "expected" figures shown are of course obtained by subtraction. The total number of cases in the full sample $(\mathrm{N}=$ 177) which fall in the "wrong" cells is $54(27+$ $21+6$ ) or $30.5 \%$. It is evident that much of this lack of agreement occurs because the normalized test-battery scores classify many people as " relative ly unstable" to whom the physician gave a clean bill of mental health; there are fewer cases of the opposite error, where the physician was une asy about people who fall in the "relatively stable" half of the psychometric scores. (In Table 8 it can be seen that this is true within each of the four occupational groups making up the total sample.)

The emotional instability score is uncorrelated with a diagnosis of rheumatism in the lumbar spine or undetermined pain of lumbar and sciatic distribution, or with rheumatic symptoms in the same areas during the previous five years.

When the sample is classified as sedentary (21\%), manual surface workers $(24 \%)$, workers spending part of their time above ground and part below $(13 \%)$ and underground $(42 \%)$, a significant relationship is found with the distribution of emotional instability scores $\left(\chi^{2}=28.33\right.$; df $=12, \mathrm{P}<0.01$, $>0.001$ ). If the occupational classification can be regarded as a continuum from office-stool to coalface, then a significant contingency coefficient of 0.36 is found between the two variables. This means that as one proceeds along the continuum in the given direction emotional instability as measured by the test-battery increases. In case the actual nature of any particular test might be largely responsible for this overall result due to extraneous

TABLE 8

COMPARISON OF PHYSICIAN'S CATEGORIES WITH UPPER AND LOWER HALVES OF EMOTIONAL INSTABILITY SCORES BROKEN DOWN FOR OCCUPATIONAL GROUPS

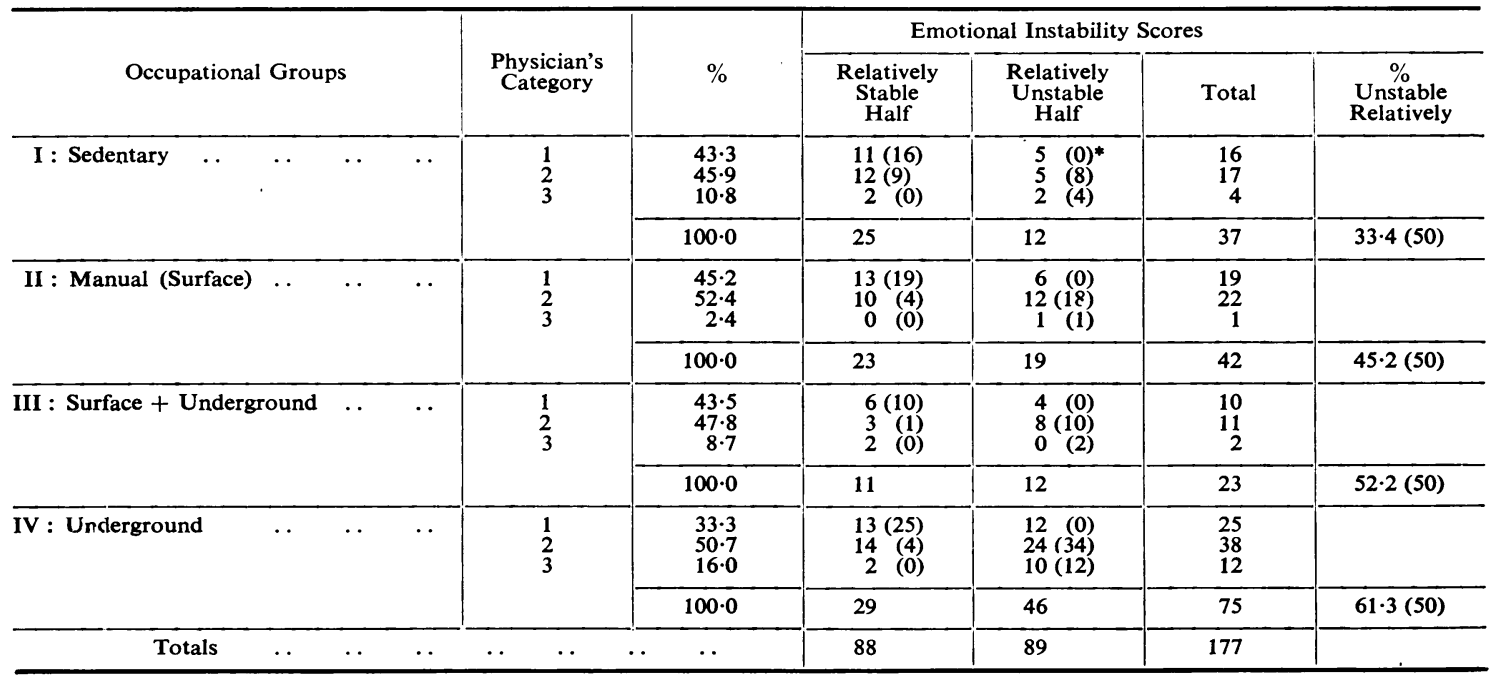

*Figures in brackets denote " expectations." 
systematic differences between underground workers and surface workers, detailed examination of the score distributions was made for each of the five tests. The trend is observable in every case, despite the differing nature of the tests. This trend can readily be examined in Table 8 , though the small totals in certain categories give rise to unstable percentages to which little value should be attached. It is, however, quite clear that the percentage of cases falling in the "relatively unstable" half of the psychometric scores steadily increases from 33.4 in Group I (sedentary) to 61.3 in Group IV (underground). It should be remembered thaf as the scores were normalized on the full sample the " expected" figure for each occupational group would of course be $50 \%$, as shown in brackets in the table. So far as the physician's " category 3" cases are concerned, the same general trend can be seen if one combines Groups I, II, and III (overcoming the difficulty of unstable percentages) to obtain a total figure of 7 in $102(7 \%)$ compared with the 12 in $75(16 \%)$ of Group IV.

\section{Discussion}

In spite of the varied responses required by these five tests, only one factor was required to account for all the common variance. This agrees with earlier work already referred to, and extends it to a new class of subjects tested under very different conditions. The present findings are also in agreement with those obtained by one of the authors (Heron, 1952) with another group of industrial workers, using a larger and more heterogeneous battery of tests which included four of those used in the present study. It should be noted, however, that when included in a larger battery, some of the present tests also provide loadings on a second factor which is uncorrelated with the first. While presenting inconsistencies which prevented confident identification, this second (bi-polar) factor was suggestive of what may be called " tendencies to hysteria or to dysthymia ", a similar finding to that reported by Eysenck $(1947,1952)$. The implication of this factorial impurity is, for practical purposes, that individual response to the demands of the tests in question may be of mixed origins. This stresses the importance of further work along these lines to develop "pure " tests in each of the dimensions which have been identified.

The significant correlation with the physician's ratings, while not large, is both interesting and encouraging. It is probably an underestimate due to coarse grouping of the variables and the imperfections of the factor score, but no one would have expressed surprise had there been no evidence of association at all. It would appear that a wide clinical experience with industrial workers can provide some basis for arriving at opinions regarding their mental health which are consonant with the results obtained by objective tests, though the latter may classify cases as relatively unstable which would succeed in obtaining a clean bill from the physician.

The absence of observed relationships between emotional instability scores and rheumatic symptoms or diagnosis was not surprising. It was, however, the kind of evidence required one way or the other in such an enquiry, especially in connexion with the subjective complaints of rheumatic pain. This result is consistent with the finding of the physician's that objective evidence of disc degeneration was found in many subjects who had made no complaint, while very few who had complained of symptoms were found to be free of degenerative, signs on $x$-ray examination.

For the interesting finding that underground workers in this sample are less emotionally stable than sedentary surface workers, with occupationally intermediate groups in correspondingly intermediate positions on the stability continuum, no wholly satisfactory explanation occurs to the writers. It is possible to suggest that underground work constitutes a sufficient stress to affect the stability of those who in less stressful circumstances would have remained relatively unaffected. Alternatively, underground work may attract men whose personalities differ systematically from those living in the same district who chose surface employment. In favour of the first hypothesis, it is worth noting that the miscellaneous group who spend part of their working lives above and part below ground are adjacent to the underground workers on the stability continuum.

Those familiar with the views of Halliday (1943; 1948 , p. 255 ff.) concerning the psychosomatic and psychoneurotic characteristics of underground miners will have seen that the present finding supports some of his contentions. It is unfortunate that he does not present data on healthy workers ; but in comparing 200 miners with 200 non-miners (all under 45) in medical referee interviews to assess "capacity for work" in men receiving sickness benefit, he attributed disablement to psychosomatic and psychoneurotic affections in $64 \%$ of miners and only $38 \%$ of non-miners. He also 'observed (Halliday, 1943) that " an unusual prevalence of anxiety-hysteria and pure hysteria was also noted in other 'dangerous occupations' such as in workers at heights (typically steeple-jacks, steel erectors, slaters, window-cleaners) as well as in 
workers at explosive factories." In the present investigation, no evidence was found to extend Halliday's emphasis on "hysteria simulating rheumatism ".

\section{Conclusions}

A small battery of objective tests, taking about 30 minutes to administer, has been found useful as a measure of emotional instability in a group of industrial workers. By its use further evidence has been obtained concerning the greater prevalence of psychoneurotic handicap among underground workers.

\section{REFERENCES}

Bennett, E. (1945). Brit. J. med. Psychol., $20,271$.

Crown, Sidney (1947). J. Personality, 16, 198.

Crown, SSidney (rit. J.) Psychol. (Gen. Sect.), 43, 103.

Eysenck H. J. (1947). Dimensions of Personality. Kegan Paul, London. (1952). The Scientific Study of Personality. Kegan Paul, London. Halliday, J. L. (1943). Psychosom. Med., 5, 71 .

(1948). Psychosocial Medicine. Heinemann, London.

Heron, Alastair (1952). J. appl. Psychol., 36, No. 6.

Kellgren, J. H., and Lawrence, J. S. (1952). British Journal of Industrial Medicine, 9,197 .

United States Employment Service (1947). Guide to the Use of General Aptitude Test Battery. Washington, D.C.: U.S. Govt. Printing Office. 